\title{
Prevalence of Overweight and Obesity among Students in the Kumasi Metropolis
}

\author{
D. B. Kumah, K. O. Akuffo, J. E. Abaka-Cann, D. E. Affram, and E. A. Osae \\ Department of Optometry and Visual Science, College of Science, \\ Kwame Nkrumah University of Science and Technology, Kumasi, Ghana
}

Correspondence should be addressed to D. B. Kumah; ben56kay@gmail.com

Received 28 July 2014; Revised 27 January 2015; Accepted 27 January 2015

Academic Editor: Michael B. Zemel

Copyright (C) 2015 D. B. Kumah et al. This is an open access article distributed under the Creative Commons Attribution License, which permits unrestricted use, distribution, and reproduction in any medium, provided the original work is properly cited.

The aim was to determine the prevalence of obesity and overweight among students in the Kumasi metropolis. In a descriptive cross-sectional study, 500 students aged 10 to 20 years were examined from two junior high schools selected by multistage sampling technique and three randomly selected senior high schools. Height and weight were measured in all participants and the body mass index (BMI) of each individual was calculated. Body mass index classes were calculated according to the International Obesity Task Force standards. Out of the 500 students, 290 (58.00\%) were males and $210(42.00 \%)$ were females. The prevalence of underweight, normal weight, overweight, and obesity was $7.40 \%, 79.60 \%, 12.20 \%$, and $0.80 \%$, respectively. Overweight was more prevalent among students than obesity. There is therefore the need to establish effective public health promotion campaigns among students in order to curtail future implications on health.

\section{Introduction}

Obesity and overweight have both been described as anomalous accumulation of excessive body fat which may be harmful to health [1]. There is no single cause to explain all cases of obesity and overweight but most studies implicate imbalance in the amounts of calories consumed and those expended [1]. Energy breakdown is said to be less than energy buildup. The disruption of the normal satiety feedback mechanisms, hyperinsulinism, insulin resistance, and genetics are some of the biophysiological causes of obesity and overweight [2].

Some researchers also attribute obesity and overweight to obesogenic environments where people are frequently exposed to and consume savory foods with hidden fats and sugars that can impair metabolism and lead to obesity [3]. Some public health experts also associate the development of obesity and overweight with socioeconomic status, urban lifestyle, family size, physical inactivity, educational status, cultural factors, and poor eating habits [4-6]. Persons who spend their leisure inactively such as in prolonged watching of television and playing of video games have been said to be at risk of obesity [7].
In addition to being pathologically chronic, obesity and overweight have been associated with other comorbidities in both younger and older populations. Heart disease, vision problems, cancer, hepatic impairment, diabetes, and other disease conditions as well as the economic burden involved in managing these conditions have been associated with obesity and overweight $[8,9]$. Obese and overweight individuals are also stigmatized; in some societies, people portray a disease stigma towards those suffering from obesity and overweight and see them as immoral, lazy, unclean, and voracious [10].

While the majority of the researches done highlight obesity and overweight as problems of the developed countries, recent studies also show that the third world countries are no exception $[11,12]$. Reports show that the issue of childhood and adolescence obesity in third world countries requires public health attention [12, 13]. During the time of this research, there were limited published findings on childhood and adolescence obesity and overweight in Ghana.

This study aimed to determine the prevalence of obesity and overweight among students aged 10-20 years in the Kumasi metropolis of Ghana, to sensitize the public on the emerging trend of childhood and adolescence obesity and 
overweight in Ghana and to provide data for public health professionals and policy planners.

\section{Methods}

2.1. Sampling. A descriptive cross-sectional study of 500 students aged 10 to 20 years was carried out from May 2010 to June 2010 in the Kumasi metropolis, Ghana. Simple random sampling was used to select three senior high schools (SHS). Multistage sampling technique was used to select 2 junior high schools (JHS). Simple random sampling was used to select one submetropolis from a total of 10 submetropolises. Within the selected submetropolis, simple random sampling was used to select two junior high schools. In each selected school, one class out of each educational level was randomly selected. Students included in the study were apparently healthy.

2.2. Sample Demographics. Kumasi is an urban and cosmopolitan settlement. Therefore, students recruited for the study came from diverse ethnic backgrounds; most of them were Ashantis and others belonged to represented minor groups from Northern Ghana. The study respondents were largely from middle class homes. Parents of the recruited students had little or no formal education and worked as tradesmen and tradeswomen and skilled professionals.

2.3. Anthropometric Measurement. Height and weight were measured using standardized protocols [14]. Weight was measured without shoes to the nearest $0.1 \mathrm{~kg}$ using a single previously standardized portable weighing scale. Height was measured without shoes and recorded to the nearest $0.1 \mathrm{~cm}$ with a height rod fixed on a wall. The body mass index (BMI) of each individual was calculated as weight in kilograms divided by height in metres squared. The BMI classes we adopted are the same as those used by the International Obesity Task Force for the international overweight and obesity cutoffs for children $[15,16]$.

2.4. Data Analysis. The statistical package for social scientists (SPSS) software, version 16.0, Chicago, USA, was used to analyze the collected data. Descriptive statistics were used to examine anthropometric characteristics. Independent $t$ test was used to test gender differences in anthropometric characteristics.

2.5. Ethical Consideration. This research was conducted with approval from the heads of the selected junior and senior high schools and from the teachers. Informed consent forms were signed by parents to approve the participation of their wards.

\section{Results and Discussion}

A total of 500 students aged 10 to 20 years took part in the study. Two hundred and ninety (58.00\%) males and 210 $(42.00 \%)$ females were included in the study. The overall mean age was $15.91 \pm 1.78$ years $(16.00 \pm 2.00$ years for the males and $15.00 \pm 2.00$ years for the females).
TABLE 1: Summary of anthropometric measurements per sex of study subjects.

\begin{tabular}{lcc}
\hline \multirow{2}{*}{ Parameters } & Males & Females \\
& Mean \pm SD & Mean \pm SD \\
& {$[95 \% \mathrm{CI}]$} & {$[95 \% \mathrm{CI}]$} \\
\hline \multirow{2}{*}{ Weight $(\mathrm{kg})$} & $54.71 \pm 9.27$ & $51.12 \pm 10.36$ \\
& {$[53.64,55.78]$} & {$[49.71,52.52]$} \\
Height $(\mathrm{cm})$ & $160.85 \pm 9.03$ & $157.24 \pm 8.97$ \\
& {$[159.80,161.89]$} & {$[156.02,158.46]$} \\
BMI $\left(\mathrm{kg} / \mathrm{m}^{2}\right)$ & $21.04 \pm 2.64$ & $20.57 \pm 3.27$ \\
& {$[20.74,21.35]$} & {$[20.13,21.02]$} \\
\hline
\end{tabular}

CI: confidence interval; BMI: body mass index.

Table 1 shows a summary of the measured anthropometric parameters per sex of study subjects. Males were significantly heavier and taller than females $(P<0.05)$ but there were no differences in BMI $(P>0.05)$.

The overall prevalence of underweight, normal weight, overweight, and obesity was 7.40\%, 79.60\%, $12.20 \%$, and $0.80 \%$, respectively. Among males and females, prevalence of overweight was $6.80 \%$ and $5.40 \%$, respectively, while the prevalence of obesity was $0.20 \%$ and $0.60 \%$, respectively. These results are slightly close to those reported in a study done among students in Nigeria [17] where there was a high prevalence of overweight and a low prevalence of obesity.

Comparable to other studies done in Ghana and other second world countries $[18,19]$, this study showed that the prevalence rate of overweight was higher among female students than male students. There are however divergent findings in studies done in developed nations [20,21] where prevalence rates of overweight among male study subjects were higher than among females. For this study, the difference in the prevalence of obesity and overweight between the genders was insignificant $(P>0.05)$; the apparently higher values for males could be confounded by a greater number of male respondents (290) as compared to the female respondents (210).

While challenges to our study design did not allow for understanding reasons for the distribution of obesity and overweight among the genders, other studies report cultural attributions as to why females may be more overweight or obese than their male counterparts [17]. A study showed that obese females considered putting on weight as a sign of affluence and happiness. Others also believed that being obese afforded the needed strength in their sport and accorded them the necessary respect [22].

This is supported by undocumented reports from some areas in Ghana, where excessive weight gain is considered to be the result of eating good and healthy food. Table 2 summarizes the prevalence of underweight, normal weight, overweight, and obesity according to the gender of the students.

Findings from this study must be considered in the light of certain challenges to the study design. The study depended on anthropometric measurements to establish whether or not the students were of the following categories: underweight, normal weight, overweight, or obesity. A study conducted in 
TABLE 2: Prevalence of underweight, normal weight, overweight, and obesity according to gender.

\begin{tabular}{|c|c|c|c|c|c|}
\hline \multicolumn{6}{|c|}{ Prevalence rate (\%) } \\
\hline Gender & Underweight & Normal weight & Overweight & Obesity & Total \\
\hline Male & 2.60 & 48.20 & 6.80 & 0.20 & 57.80 \\
\hline Female & 4.80 & 31.40 & 5.40 & 0.60 & 42.20 \\
\hline Total & 7.40 & 79.60 & 12.20 & 0.80 & 100.00 \\
\hline
\end{tabular}

Ghana extensively looked at how the various weight statuses were linked to socioeconomic status of subjects and level of education of students' parents [23]. Another study also found significant associations between smoking and overweight and obesity [17] while other reports reveal positive associations between some psychosocial factors (e.g., loneliness and social isolation) $[23,24]$.

Even though this study did not look at socioeconomic status, smoking, dietary factors, loneliness, behavioural patterns, age of menarche, and order of births of the students and how these may influence their different weight statuses, it is reasonable from other studies [17, 23-26] to say that a complex interplay of these factors could contribute to our findings in this study.

To the best of our knowledge, the study has provided an insight into the prevalence of obesity and overweight among children and adolescents aged 10-20 years in the Kumasi metropolis of Ghana.

\section{Conclusion}

The study revealed a high prevalence of overweight (12.20\%) among the students. Therefore, there is a need to establish effective prevention and health promotion programmes among the students. This would enable maintaining healthy weights and avoiding the possible immediate and long-term health complications associated with overweight and obesity.

\section{Conflict of Interests}

The authors declare that there is no conflict of interests regarding the publication of this paper.

\section{References}

[1] World Health Organization, Obesity and Overweight, 2009, http://www.who.int/mediacentre/factsheets/fs311/en/index .html.

[2] P. Codogno and A. J. Meijer, "Autophagy: a potential link between obesity and insulin resistance," Cell Metabolism, vol. 11, no. 6, pp. 449-451, 2010.

[3] H. David, "An integrative view of obesity," The American Journal of Clinical Nutrition, vol. 91, supplement, pp. 280S-283S, 2010.

[4] H. M. Al-Hazzaa and A. A. Al-Rasheedi, "Adiposity and physical activity levels among preschool children in Jeddah, Saudi Arabia," Saudi Medical Journal, vol. 28, no. 5, pp. 766-773, 2007.

[5] A. Fazah, C. Jacob, E. Moussa, R. El-Hage, H. Youssef, and P. Delamarche, "Activity, inactivity and quality of life among Lebanese adolescents," Pediatrics International, vol. 52, no. 4, pp. 573-578, 2010.
[6] A. A. Al-Nuaim, Y. Al-Nakeeb, M. Lyons et al., "The prevalence of physical activity and sedentary behaviours relative to obesity among adolescents from Al-ahsa, Saudi Arabia: rural versus urban variations," Journal of Nutrition and Metabolism, vol. 2012, Article ID 417589, 9 pages, 2012.

[7] M. K. Sodhi, "TV viewing versus play-trends and impact on obesity," Online Journal of Health and Allied Sciences, vol. 9, no. 2, 2010.

[8] P. W. Franks, R. L. Hanson, W. C. Knowler, M. L. Sievers, P. H. Bennett, and H. C. Looker, "Childhood obesity, other cardiovascular risk factors, and premature death," The New England Journal of Medicine, vol. 362, no. 6, pp. 485-493, 2010.

[9] Y. C. Wang, K. McPherson, T. Marsh, S. L. Gortmaker, and M. Brown, "Health and economic burden of the projected obesity trends in the USA and the UK," The Lancet, vol. 378, no. 9793, pp. 815-825, 2011.

[10] R. M. Puhl and C. A. Heuer, "Obesity stigma: important considerations for public health," The American Journal of Public Health, vol. 100, no. 6, pp. 1019-1028, 2010.

[11] S. Moore, J. N. Hall, S. Harper, and J. W. Lynch, "Global and national socioeconomic disparities in obesity, overweight, and underweight status," Journal of Obesity, vol. 2010, Article ID 514674, 11 pages, 2010.

[12] World Health Organization, Global Strategy on Diet, Physical Activity and Health: Childhood Overweight and Obesity, 2010, http://www.who.int/dietphysicalactivity/childhood/en/.

[13] A. K. Ziraba, J. C. Fotso, and R. Ochako, "Overweight and obesity in urban Africa: a problem of the rich or the poor?" BMC Public Health, vol. 9, article 465, 2009.

[14] T. Lohman, A. Roche, and R. Martorell, Anthropometric Standardization Reference Manual, Human Kinetics Books, Champaign, Ill, USA, 1988.

[15] T. J. Cole, M. C. Bellizzi, K. M. Flegal, and W. H. Dietz, "Establishing a standard definition for child overweight and obesity worldwide: international survey," British Medical Journal, vol. 320, no. 7244, pp. 1240-1243, 2000.

[16] T. J. Cole, K. M. Flegal, D. Nicholls, and A. A. Jackson, "Body mass index cut offs to define thinness in children and adolescents: international survey," British Medical Journal, vol. 335, no. 7612, pp. 194-197, 2007.

[17] K. Peltzer and S. Pengpid, "Overweight and obesity and associated factors among school-aged adolescents in Ghana and Uganda," International Journal of Environmental Research and Public Health, vol. 8, no. 10, pp. 3859-3870, 2011.

[18] M. E. G. Armstrong, M. I. Lambert, K. A. Sharwood, and E. V. Lambert, "Obesity and overweight in South African primary school children-the health of the nation study," South African Medical Journal, vol. 96, no. 5, pp. 439-444, 2006.

[19] S. H. Hamaideh, R. Y. Al-Khateeb, and A. B. Al-Rawashdeh, “ Overweight and obesity and their correlates among Jordanian adolescents," Journal of Nursing Scholarship, vol. 42, no. 4, pp. 387-394, 2010. 
[20] C. Curry, S. N. Gabhainn, E. Godeau et al., Inequalities in Young People's Health: HBSC International Report from the 2005/2006 Survey, WHO Regional Office for Europe, Copenhagen, Denmark, 2008.

[21] A. Yngve, I. De Bourdeaudhuij, A. Wolf et al., "Differences in prevalence of overweight and stunting in 11-year olds across Europe: the Pro Children study," European Journal of Public Health, vol. 18, no. 2, pp. 126-130, 2008.

[22] T. Puoane, L. Tsolekile, and N. Steyn, "Perceptions about body image and sizes among black African girls living in Cape Town," Ethnicity and Disease, vol. 20, no. 1, pp. 29-34, 2010.

[23] A.-K. M. Ibrahim, A.-H. M. Ali, and F. E. Sivarajan, "Predictors of obesity in school-aged Jordanian adolescents," International Journal of Nursing Practice, vol. 16, no. 4, pp. 397-405, 2010.

[24] B. K. Potter, L. L. Pederson, S. S. H. Chan, J.-A. L. Aubut, and J. J. Koval, "Does a relationship exist between body weight, concerns about weight, and smoking among adolescents? An integration of the literature with an emphasis on gender," Nicotine and Tobacco Research, vol. 6, no. 3, pp. 397-425, 2004.

[25] H. Mohammed and F. Vuvor, "Prevalence of childhood overweight/obesity in basic school in Accra," Ghana Medical Journal, vol. 46, no. 3, pp. 124-12, 2012.

[26] R. K. Goyal, V. N. Shah, B. D. Saboo et al., "Prevalence of overweight and obesity in Indian adolescent school going children: its relationship with socioeconomic status and associated lifestyle factors," Journal of Association of Physicians of India, vol. 58, no. 3, pp. 151-158, 2010. 


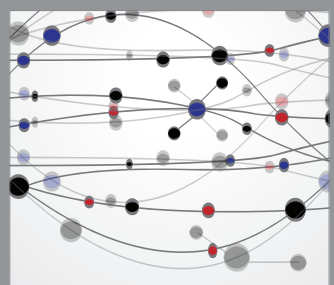

The Scientific World Journal
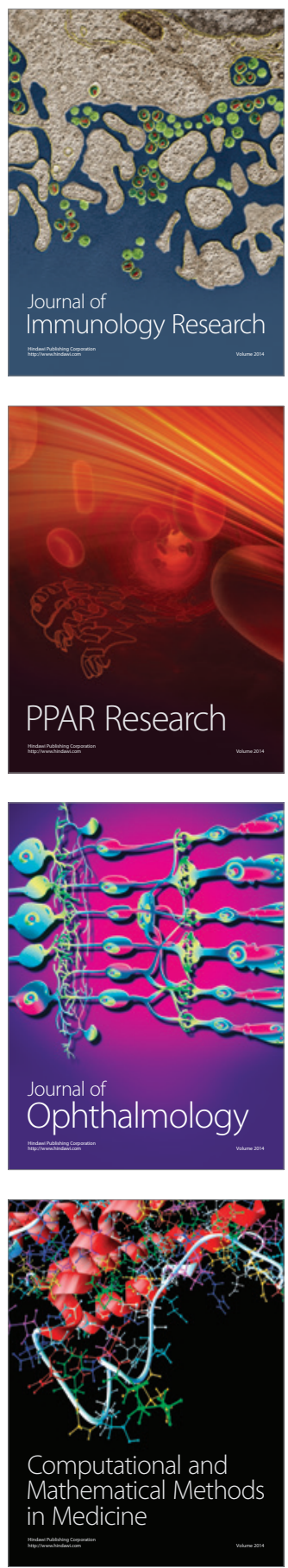

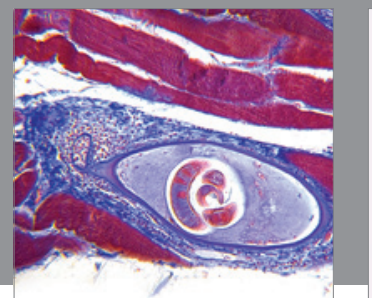

Gastroenterology

Research and Practice
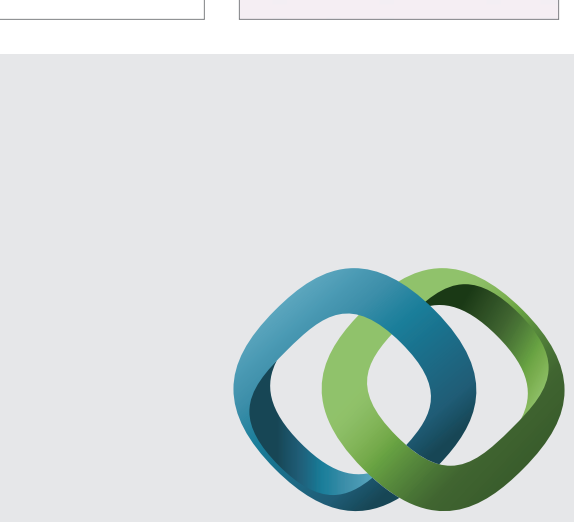

\section{Hindawi}

Submit your manuscripts at

http://www.hindawi.com
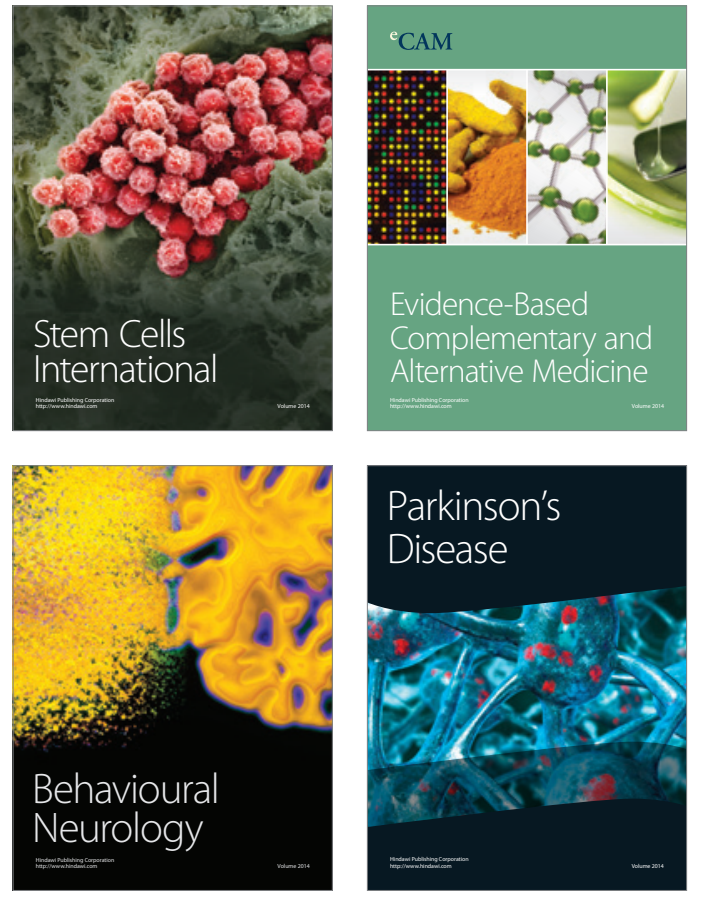
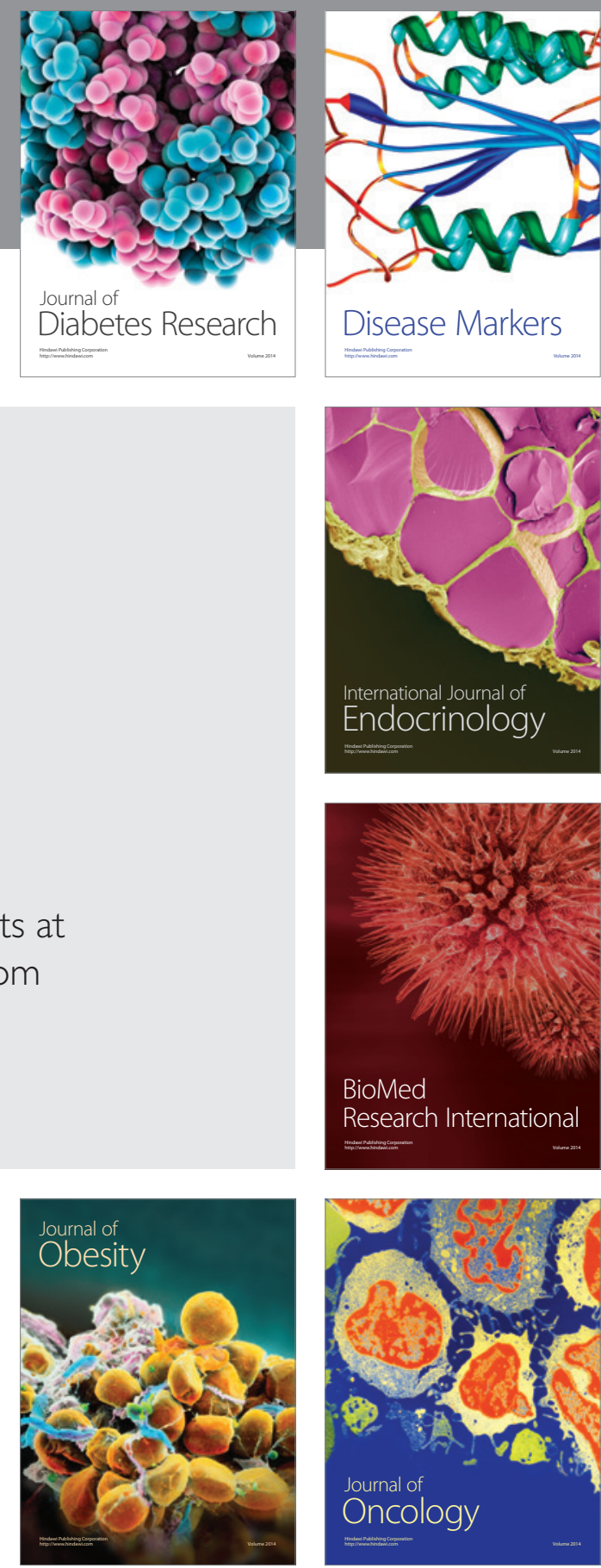

Disease Markers
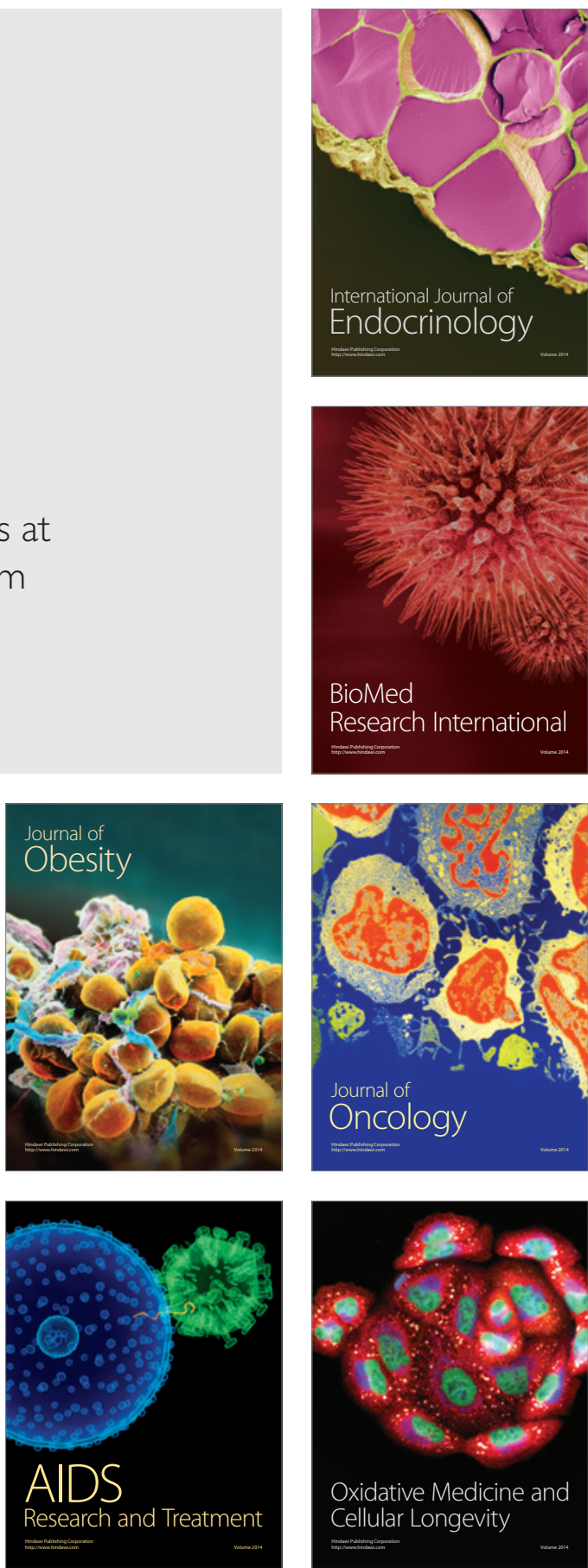